\title{
O MAIOR CINEMA NA HISTÓRIA DE BARBACENA: PANORAMA DOS PRIMEIROS ANOS DO CINE-THEATRO APOLLO (1923 A 1925)
}

\author{
Igor Maciel da Silva ${ }^{1}$
}

\begin{abstract}
Resumo: O objetivo deste artigo é apresentar um panorama dos primeiros anos de funcionamento do Cine-Theatro Apollo, o cinema de rua de Barbacena, Minas Gerais, que esteve em atividade por maior número de anos, respectivamente de 1923 a 1998, a fim de entender como se deu o funcionamento, qual a equipe de trabalho, público, filmes e programações. O recorte temporal começa em 1923, ano de inauguração do recinto, e finda em 1925, período em que a casa foi arrendada pela primeira vez. Para isso recorreu-se especialmente a pesquisa documental com jornal, revista e entrevista. Como conclusão apresenta-se que a casa abrigou diferentes tipos de programações adulto, infantil, artística e beneficente; contemplou a presença de diferentes estratos sociais, incluindo pessoas brancas e negras; inovou na compra de filmes e, por fim, incluiu mulheres de modo público em sua equipe de trabalho.
\end{abstract}

Palavras-chave: Cinema; Diversões; Barbacena-MG; História do cinema; História regional.

\section{EL CINE MÁS GRANDE DE LA HISTORIA DE BARBACENA: RESUMEN DE LOS PRIMEROS AÑOS DEL CINE-THEATRO APOLLO (1923 A 1925)}

Resumen: El objetivo de este artículo es presentar un panorama de los primeros años de funcionamiento del Cine-Theatro Apollo, el cine callejero de Barbacena, Minas Gerais, que estuvo en funcionamiento durante un mayor número de años, respectivamente, de 1923 a 1998, con el fin de comprender cómo funcionó, el equipo de trabajo, la audiencia, las películas y los horarios. El plazo se inicia en 1923, año de inauguración del recinto, y finaliza en 1925, cuando se alquila la casa por primera vez. Para ello se utilizó la investigación documental con periódicos, revistas y entrevistas. En conclusión, parece que la casa albergó diferentes tipos de programas adultos, infantiles, artísticos y benéficos; contempló la presencia de diferentes estratos sociales, incluidos blancos y negros; innovó en la compra de películas y, finalmente, incluyó a las mujeres de manera pública en tu equipo de trabajo.

Palabras clave: Cine; Entretenimiento; Barbacena-MG; Historia del cine; Historia regional.

\footnotetext{
${ }^{1}$ Mestre e doutorando em Estudos do Lazer pela Universidade Federal de Minas Gerais. Professor do curso de Educação Física da Universidade Federal de Juiz de Fora - Campus Governador Valadares. E-mail: professorigormaciel@gmail.com. ORCID: https://orcid.org/0000-0002-6560-0475. Este artigo é um fragmento da tese desenvolvida no Programa de Pós-graduação Interdisciplinar em Estudos do Lazer (UFMG). Agradeço as contribuições de Maria Ines Piacesi, Leila Piacesi, Adriana Piacesi, Gogóia e Everton Pimenta.
} 


\title{
THE LARGEST CINEMA IN THE HISTORY OF BARBACENA: OVERVIEW OF THE FIRST YEARS OF THE CINE-THEATRO APOLLO (1923 TO 1925)
}

\begin{abstract}
The objective of this article is to present an overview of the first years of operation of the Cine-Theatro Apollo, the street cinema of Barbacena, Minas Gerais, which was in operation for the greatest number of years, respectively from 1923 to 1998, in order to understand how it worked, the work team, audience, films and schedules. The time frame begins in 1923, the year of inauguration of the enclosure, and ends in 1925, when the house was rented for the first time. For this, documentary research with newspapers, magazines and interviews were used. In conclusion, it appears that the place housed different types of adult, children's, artistic and charitable programs; contemplated the presence of different social strata, including white and black people; innovated in the purchase of films and, finally, included women in a public way in your work team.
\end{abstract}

Keywords: Cinema; Entertainment; Barbacena-MG; Cinema's history; Regional history.

\section{"Luz": apresentação, objetivos e metodologia}

O cinema foi uma das principais opções de divertimento no início do século XX em diferentes regiões do Brasil (SEVCENKO, 1992). Em Minas Gerais, por exemplo, citam-se pesquisas que apontam o lugar de importância do cinema em Juiz de Fora, Belo Horizonte, Mariana, Uberlândia, Uberaba, Diamantina, Montes Claros, Varginha, Cataguases, Campanha, Pouso Alegre, Itajubá e Barbacena.

Barbacena é uma cidade mineira conhecida pelas atividades de plantio e venda de flores, como cravos e rosas, e pelo funcionamento de casas de saúde, em especial o Hospital Colônia. Além dessas características, no início do século XX, o município se destacou nas atividades econômicas, agrícolas e industriais do Estado, administrando um grande número de distritos, produzindo carnes, derivados do leite, fumo e cerâmica, assim como forneceu esses insumos para o comércio das capitais São Paulo e Rio de Janeiro (RIBEIRO, 2012).

As narrativas que investigaram a história do cinema em Barbacena no início do século XX se dedicaram especialmente a atividade de diretor de documentários de Paulo Benedetti, imigrante italiano que patenteou em filmes gravados na região na década de 1910 a técnica da cinemetrophonia, uma tecnologia que incluiu sonoplastia nas projeções fílmicas (GALDINO, 1980; ORLANDO, 2005; BARRO, 2017; GOMES, 2008, GOMES, 2011). Outras pesquisas analisaram as ações do casal Aroldo Piacesi e Ines Piacesi no Cine-Theatro Apollo ${ }^{2}$, mas sem conferir maiores detalhes as atividades projetoras da casa, visto que o foco esteve na análise dos impressos geridos pela empresa (PIMENTA 2007; PIMENTA, 2015), e por fim, sobre as

\footnotetext{
${ }^{2}$ Optou-se por manter a grafia de alguns termos e trechos conforme as fontes consultadas.
} 
formas de participação das mulheres nas diversões, sendo um dos capítulos sobre as citadinas nos cineteatros locais (SILVA, 2018).

Em outro sentido, este artigo objetiva apresentar um panorama dos primeiros anos de funcionamento do Cine-Theatro Apollo, o cinema de rua de Barbacena que esteve em atividade em maior número de anos, a fim de responder como se deu o funcionamento, qual a equipe de trabalho, público, filmes e programações. O recorte temporal começa em 1923, ano de inauguração do recinto, e finda em 1925, período em que a casa foi arrendada temporariamente. Para isso, recorreu-se especialmente a pesquisa documental em que foram analisados os jornais Cidade de Barbacena, disponibilizado pela Hemeroteca Histórica da Biblioteca Pública Estadual Luiz de Bessa (Belo Horizonte - MG) e o Apollo Jornal, cujos exemplares foram doados por Everton Fernando Pimenta. Secundariamente consultou-se as revistas cariocas Nação Brasileira e Cinearte, alocadas na Hemeroteca Digital da Biblioteca Nacional (Rio de Janeiro-RJ), o arquivo digital do Centro de Pesquisa e Documentação de História Contemporânea do Brasil (CPDOC-FGV), uma entrevista com Maria da Glória Bittar de Castro e fotografias dispostas especialmente de modo ilustrativo.

O jornal Cidade de Barbacena (C.B.) é considerado o impresso de maior circulação do município, com 95 anos de trabalho, começou a circular em 1898 e terminou as suas atividades em 1993 (RESENDE, 2012). O periódico foi fundado por Emílio Gonçalves Júnior, professor de Latim e Língua Portuguesa que dirigiu a primeira edição que circulou de 23 de janeiro de 1898 até 16 de maio de 1914. A segunda tiragem começou em 17 de maio de 1914 e findou em 5 de setembro de 1931 e esteve sob a direção dos filhos do idealizador do impresso, nomeadamente Carlos Benjamin Gonçalves e Paulo Emílio Gonçalves (SILVA, 2018). Nesta pesquisa foram consultados os números referentes a segunda edição do jornal pois incluem os primeiros anos de funcionamento do Cine Apollo.

O Apollo Jornal (A.J.) foi um semanário que circulou de 12 de agosto de 1923 a 1 de janeiro de 1924. Trata-se de um impresso dirigido pelo Cine-Theatro Apollo e com a redação sob a responsabilidade de Ines Piacesi. Anunciado como "orgam da empreza do Cine-Theatro Apollo"3, na sua nona edição acrescentou que o lema do estabelecimento era "crescer... evoluir sempre!"4. Esse jornal foi distribuído gratuitamente aos frequentadores do recinto pelos correios e em suas páginas além de textos dedicados ao cinema e ao funcionamento da casa de diversão, constam artigos de filosofia, enquetes sobre o amor nas diferentes fases da vida, poemas, propagandas de negócios e empresas locais como armazéns, lojas de artigos de moda,

\footnotetext{
${ }^{3}$ A.J., Barbacena, n. 1, 1923, p. 1.

${ }^{4}$ A.J., Barbacena, n. 9, 1923, p. 1.
} 
confeitarias, leiteria, instituições de ensino, alfaiataria, serviços clínicos e também comentários sobre atitudes políticas locais e estrangeiras.

\section{“Câmera": família Piacesi, família de cinema}

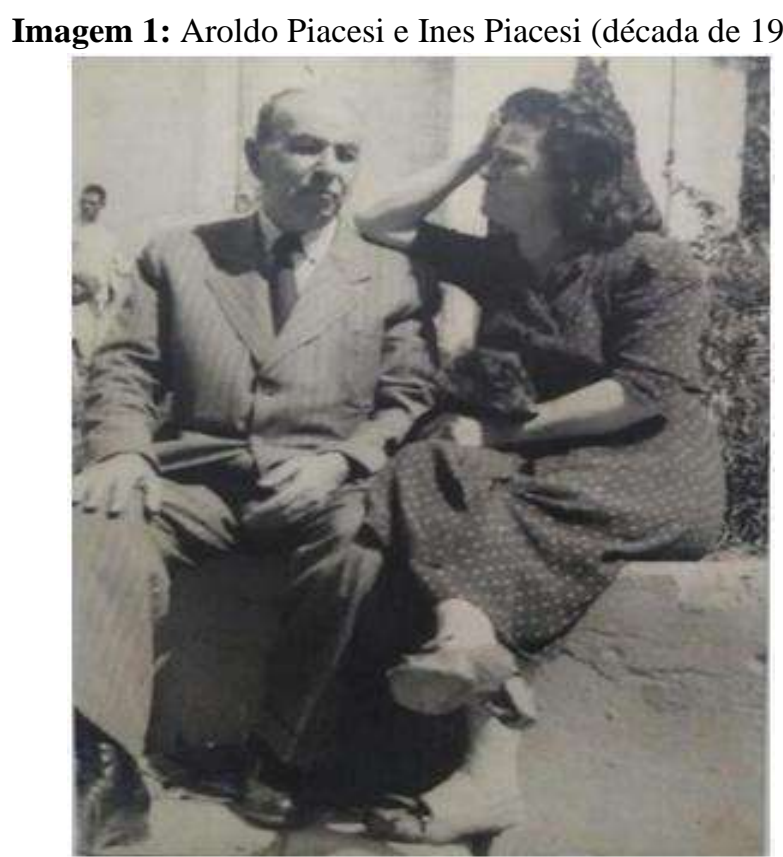

Fonte: Autoria desconhecida. Fotografia doada por Maria Inês Piacesi, neta do casal, em 30 de dezembro de 2019.

O Cine-Theatro Apollo foi inaugurado em 12 de agosto de 1923 pela iniciativa do imigrante italiano Aroldo Piacesi, e esteve sob a direção de sua família até a década de 1960, havendo uma interrupção nessa gestão no último quartel da década de 1920, quando arrendou a casa para o empresário Antonio Leal. Em meados de 1930 a família Piacesi assumiu novamente a sua direção e nos anos finais da década de 1960 o vendeu em definitivo para Urias Barbosa de Castro, cuja família manteve a casa em atividade até 3 de novembro de 1998.

Em 1901, o italiano Orlando Piergentili (1865-1941), natural da comuna de Fabro (Itália), chegou a Barbacena com a filha Ines Piergentili (1895-1981) e os sobrinhos Nello Piacesi (1878-1922) e Aroldo Piacesi (1881-1954), os dois últimos eram filhos de Chiara Piergentili, que por sua vez se casou com Gaetano Piacesi e teve três descendentes: Nello, Aroldo e Ida.

Aroldo e Orlando dirigiram a sociedade comercial Piergentili Piacesi \& Comp., que foi responsável pela Padaria, Açougue e por outra casa projetora, o Theatro Cinema Moderno. Aroldo foi uma pessoa de prestígio na cidade e era considerado parte da intelectualidade 
barbacenense, pois atuou como secretário da Sociedade Italiana de Beneficencia Vittorio Emanuelle II entre 1906 e 1913, compôs a Associação Comercial de Barbacena em 1920 (PIMENTA, 2015), representou o consulado italiano na localidade, geriu comércios e inaugurou o Cine-Theatro Apollo.

Após o rompimento da sociedade com o tio, Aroldo firmou acordo comercial com o irmão mais velho, Nello Piacesi, que já era responsável por um comércio de secos e molhados na cidade. Os irmãos Piacesi inauguraram a Confeitaria Apollo em 25 de dezembro de 1921, contudo, Nello foi à óbito por gripe espanhola em 1 de outubro de 1922, por isso Aroldo seguiu de modo autônomo com a confeitaria e outras atividades comerciais, a dizer a venda de bicicletas e a inauguração do cineteatro (SILVA, 2018), sendo que após tal feito arrendou a Confeitaria Apollo para o citadino Luiz Acerbi ${ }^{5}$.

O sr. Piacesi contou com a esposa na organização das atividades do cineteatro, sra. Ines Piacesi, uma importante intelectual barbacenense, filha de Orlando Piergentili e Marieta Zuchetti, chegou na região ainda criança e a sua formação escolar se deu no Colégio Imaculada Conceição. Casou-se com o primo em 1912 e conduziu a escrita dos semanários Apollo Jornal (1923-1924) e O Rubicon (1935-1954) que pertenciam a empresa Apollo, onde divulgaram a programação da casa de diversões e os ideais da família (PIMENTA, 2007). A sra. Piacesi Também contribuiu com a escrita de outros jornais, a dizer os locais O Sericicultor, Jornal de Barbacena e Cidade de Barbacena, em que assinava os pseudônimos Seny e D. Paula; de São João Del Rei, o Diário do Comércio; de Juiz de Fora, o Diário Mercantil (PIMENTA, 2007); contribuiu com as revistas cariocas Nação Brasileira e Cinearte.

Ines Piacesi, além de jornalista foi professora primária no Grupo Escolar Bias Fortes entre 1928 e 1951, quando se aposentou por motivos de saúde (PIMENTA, 2007). A mesma esteve envolvida com atividades do ensino antes de lecionar, dado que antes de assumir o cargo de normalista participou de bancas de avaliação no Grupo Escolar e incluía em seu círculo relacional às professoras da cidade $^{6}$. Como docente propôs metodologias de aprendizado inovadoras para o alunado, como excursões para a cidades de São João Del Rei e Ouro Preto, criação de um jornal pela sua classe, de título $O$ grilo (1940) (SAVASSI, 991) e apresentação de trabalhos no Congresso de Educação em Goiânia (1942) (PIMENTA, 2007). Acrescenta-se a isso que a mesma dialogou por correspondências datadas de 23 de dezembro de 1939 com o ministro da educação, na época sr. Gustavo Capanema, em que elogiou o trabalho do mesmo e

\footnotetext{
${ }^{5}$ BRINDES. A.J., Barbacena, n. 12, 28 out. 1923, p. 4.

${ }^{6}$ GRUPO ESCOLAR. A.J., Barbacena, n. 16, 1924, p. 2.
} 
junto ofereceu uma cópia de um texto de sua autoria cujo título Inteligencia $n^{o} 1$ do NOVO BRASIL fazia menção ao ministro e foi publicado no seu jornal $O$ Rubicon ${ }^{7}$.

\section{“Ação": o Cine-Theatro Apollo}

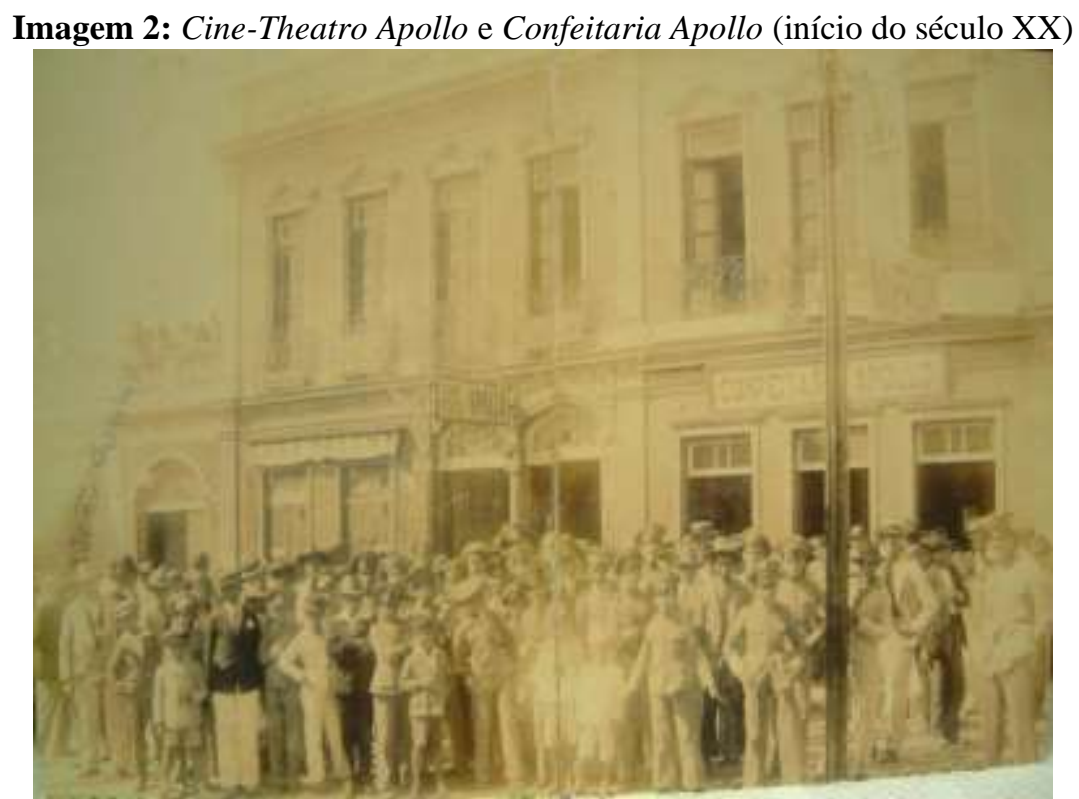

Fonte: Domínio público. Fotografia disponível no grupo de Facebook "BarbarasCenas", publicada por Elton Belo Reis em 16 dez 2019. Disponível em:

https://www.facebook.com/photo.php?fbid=2935714689785471\&set=g. $282478721886589 \&$ type $=1 \&$ theater \&if $\mathrm{g}=1$ Acesso em 31 jan. 2020.

O Cine-Theatro Apollo foi aberto de 12 de agosto de 1923 e na mesma ocasião inaugurou o Apollo Jornal ${ }^{8}$, periódico que afirmou que tal acontecimento representou "o maior sucesso registrado nos annaes do progresso barbacenense", diversões bem estruturado, com as melhores programações, "digno da cultura de seu povo"10, e por inúmeras vezes afirmou que era o maior teatro de Minas Gerais. Esteve endereçado na rua 15 de novembro, número 20, e foi divulgada como uma casa de diversões com "localisação central, segurança, hygiene, ventilação, conforto, bom gosto, elegancia"11, sua mobilia foi comprada no Rio de Janeiro $^{12}$ e tinha capacidade para seiscentos lugares na plateia ${ }^{13}$.

\footnotetext{
7 PIACESI, I. Carta elogiosa de Ines Piacesi a Gustavo Capanema, dez. 1939. Centro de Pesquisa e Documentação (CPDOC), Arquivo Gustavo Capanema - Série correspondências, Rio de Janeiro. Disponível em: http://www.fgv.br/cpdoc/acervo/arquivo-pessoal/GC/textual/carta-elogiosa-de-ines-piacesi-a-gustavo-capanemaenviando-descricao-fisionomica-do-ministro-com-as-devidas-implicacoes-sobre-o-carater-barbacena- Acesso em 14 maio 2020.

${ }^{8}$ A.J., Barbacena, n. 1, 1923.

${ }^{9}$ APÓS A LUCTA VENCIDA. A.J., Barbacena, n. 2, 1923, p. 1.

${ }^{10}$ HOSANA. A.J., Barbacena, n. 14, 1923, p. 1.

${ }^{11}$ O APOLLO AO PUBLICO DISTINCTO E CONSCIENCIOSO. A.J., Barbacena, n. 9, 1923, p. 1.

${ }^{12}$ CINE-THEATRO-APOLLO. C.B., Barbacena, n. 1904, 1923, p. 1.

${ }^{13}$ CINE-THEATRO APOLLO. C.B., Barbacena, n. 1904, 1923, p.1.
} 
Anteriormente a sua inauguração foram disponibilizadas cadernetas de assinaturas de bilhetes, o que não foi anunciado se teve adesão do público, contudo, independente de adesão, percebe-se que a confecção de cadernetas tratava-se de uma interessante estratégia comercial para a popularização da frequência às sessões fílmicas. O preço da entrada individual custava $1 \$ 100^{14}$ como um valor fixo nas sessões comuns ou poderiam ser compradas em um número maior, em blocos com as seguintes opções: 20 entradas a 20\$000, 40 entradas a 37\$000, 60 entradas a $53 \$ 000^{15}$. O jornal Cidade de Barbacena também conferiu alguns detalhes do Apollo antes de seu funcionamento ao público:

[...] tem, no interior a altura de que carecem as casas de diversões, - é arejado, dispõe de excellente palco, camarins, platéa ampla, com lotação para cerca de seiscentas pessôas, além de possuir camarotes, varandas, confortavel sala de espera, etc. Dispõe ainda o <<Theatro Apollo〉> de bem feita e hygienica installação sanitaria. ${ }^{16}$

Mesmo com tais descrições de sua infraestrutura, a empresa afirmou que a lotação completa do cinema ainda não estava terminada, restando a instalação de "galerias, frisas, camarote e geral" ${ }^{\prime \prime}$, e ainda que o palco não estivesse finalizado seriam organizadas apresentações artísticas no âmbito para que as sessões ficassem mais atrativas ${ }^{18}$.

O Cine Apollo organizava programas diários no formato de soirées que poderiam variar nos seguintes horários: 18:00 e 20:00 horas, 18:30 e 20:30 horas, 18:30 e 20:15 horas, e por fim, 20:30 e 21:30. Outras propostas foram organizadas pela empresa, por exemplo, em todos os domingos e feriados ofereceu "matinée para a petisada, com programas adaptados especiaes"19 que aconteciam às 13:30 horas ou 14:00 horas, e de modo similar a matinée blanche também dedicada às crianças, mas com data para às quintas-feiras no horário de 13:30 horas e com sorteio de brindes no momento ${ }^{20}$. Citam-se também as sessões especiaes $e$ variadas, sessão de arte, sessões dedicadas a estabelecimentos e associações educativas e a Sessão Selecta, uma atração das segundas-feiras destinada a exibição de filmes da marca Serrador $^{21}$.

$\mathrm{Na}$ inauguração a casa de diversões foi ornamentada com flores pelos artistas Augusto Araujo Lima e Fausto Costa, e estava planejado para o mesmo dia a exposição de telas da

\footnotetext{
${ }^{14}$ Contos de réis.

${ }^{15}$ CINE-THEATRO APOLLO. C.B., Barbacena, n. 1917, 1923, p.1.

${ }^{16}$ CINE-THEATRO APOLLO. C.B., Barbacena, n. 1904, 1923, p.1.

${ }^{17}$ A APOTHEOSE PERENE DO APOLLO. A.J., Barbacena, n. 3, 1923, p.1.

${ }^{18}$ OS ESPECTACULOS DO APOLLO. A.J., Barbacena, n. 5, 1923, p. 2.

${ }^{19}$ A.J., Barbacena, n. 2, 1923, p. 4.

${ }^{20}$ MATINÉE BLANCHE. A.J., Barbacena, n. 10, 1923, p. 2.

${ }^{21}$ SESSÃO SELECTA, A.J., Barbacena, n. 9, 1923, p. 1.
} 
pintora local Petrina Coutinho, que foi adiada a pedido da autora das obras por temor a quantidade de presentes na casa que na ocasião somou mais de $2.000^{22}$ e não foram identificados detalhes se aconteceu em outro momento.

O programa inaugural do domingo 12 de agosto de 1923 contou com "matinée - ás 2 horas com fitas especiaes para a nossa querida petisada. Soirée - 2 sessões, A's 6 horas em ponto e 8 horas em ponto. Preço effectivo, fixo e inalteravel, $1 \$ 100^{\prime 223}$. Não foi anunciado se a fita da matinée era diferente da projetada na soirée, o drama Cléo de Paris. Tratava-se de um filme gravado em 1922 e distribuído pela Metro Pictures Corporation Exclusive Distribuitors, produzido por Edmundo Goulding e no Brasil era parte do Programa Serrador que já havia sido exibido por duas semanas sem interrupção no Cine Odeon do Rio antes de chegar ao Apollo.

No primeiro número do Apollo Jornal a empresa fez saber que contaria com apresentação de orquestra dirigida pelo Sr. Octavio Costa que já havia trabalhado no Cinema Odeon do Rio, e que só seriam exibidos os melhores programas, por isso as fitas projetadas nas salas cariocas seriam maioria, acrescentando a isso que duas vezes por semana contaria com o Programa Serrador, definido como o melhor, mais luxuoso, mais caro e distinto do país. E "no seu ecran projectar-se-ão as ultimas produção dos idolos Bertini, Menichelli, etc., bem como os films "super" e extra especial da Fox, Pathé, Tirst, Golduim, Argentina Film, etc., etc."24.

O Apollo fez um comunicado ao público que aponta que o recinto era uma casa de diversões popular e sem a intenção de se tornar elitizada. Isso ocorreu a partir de boatos de que as senhoras barbacenenses queriam trajar chapéu no dia da inauguração a empresa foi contra, pois isso poderia intimidar populares a não comparecerem, visto que tal indumentária era um traje usado especialmente pelas classes mais abastadas, e não era a intenção não contar com a presença de estratos sociais menos favorecidos na ocasião. Conforme a nota:

corre o boato de que à inauguração do Cinema as senhoras se apresentarão de chapéu; boatos destes só têm um fim: prejudicar a Empreza e assustar o povo. Si um grupo de elegantes abastadas pretende fazel-o, não quer dizer isto que todas devam fazel-o também.

O chapéo, como tudo mais, vae segundo o gosto e o modo de pensar de cada um. Depois uma estréa a preço tão modico - $1 \$ 100$ apenas, não pede de modo algum luxo.

O "Apollo" é uma casa de diversões popular - ao alcance de todas as bolsas. Não tem fundamento pois, o chapeu para a estréa que será com a simplicidade de sempre ${ }^{25}$.

\footnotetext{
${ }^{22}$ A EXPOSIÇÃO DE PINTURA DE PETRINA COUTINHO. A.J., Barbacena, n. 2, 1923, p. 1.

${ }^{23}$ PROGRAMA DA SESSÃO INAUGURAL DO CINE-THEATRO APOLLO. A.J., Barbacena, n. 1, 1923 , p. 4.

${ }^{24}$ IMPORTANTE. A.J., Barbacena, n. 1, 1923, p. 3.

${ }^{25}$ A EMPREZA DO APOLLO AO PUBLICO. A.J., Barbacena, n. 1, 1923, p. 3.
} 
A intenção desse cinema em receber assistentes da classe popular se reforça em textos publicados em seu periódico. Citam-se um de autoria da empresa que escreveu que o Apollo “[...] não é uma casa particular de diversões, mas um templo publico, um recinto sagrado á popularidade, á satisfação, das exigencias do publico" 26 . E outro assinado por Philocelina Mattos de Almeida, professora local, para quem "a estréa do Cine-Apollo foi uma sublime apotheose, um empolgante trophéo que fazia vibrar a alma fremente da grande massa popular áli attrahida"27. Essa autora ainda ofereceu detalhes do comportamento dos assistentes que se mostraram muito interessados por esse divertimento, como uma "compacta multidão que, avida, se acotovelava, disputando ingresso no ambito das projeções cinematographicas" 28 .

A presença de um grande público nessa casa de diversões era algo rotineiro pois em uma fotografia de 1924 (Imagem 3) nota-se o quantitativo de assistentes sentados e em pé ao fundo da sala de projeções para assistir a uma sessão comum. Ainda, diferentemente da Imagem 2, em que se nota poucas pessoas negras na porta desse cinema, na fotografia seguinte constam pessoas negras sentadas na plateia junto a pessoas brancas logo nas primeiras filas (à esquerda uma mulher no meio de duas crianças e um homem atrás).

Imagem 3: Aspecto da platéa do Cine-Theatro Apollo, numa de suas sessões communs (1924)

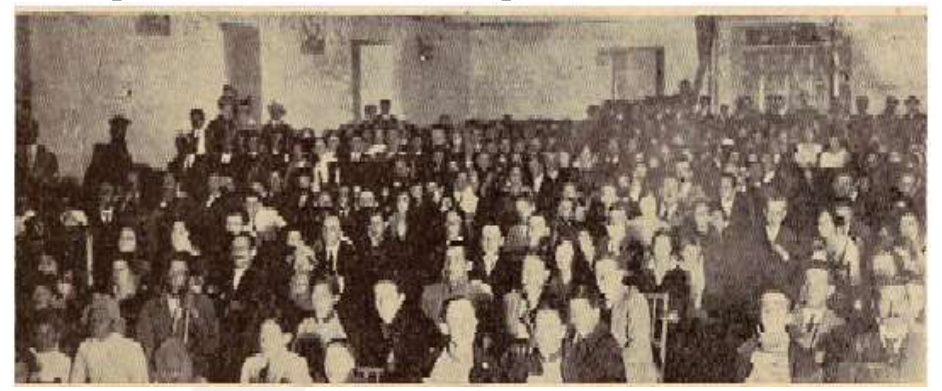

Fonte: CINE-THEATRO APOLLO, Nação Brasileira, Rio de Janeiro, 1924, p. 91.

Segundo a pesquisa de Bouillet (2020), a cor da pele era sinônimo de baixa renda no início do século XX, e em cidades mineiras como Uberlândia percebeu-se a frequência de pessoas negras nos cinemas mas com restrições, seja no setor que compravam os bilhetes de entrada que era diferente das pessoas brancas, denominado de balcão ou poleiro, ou nos lugares que se sentavam para assistir as projeções. Tais aspectos não foram noticiados em Barbacena, contudo pelo registro da plateia do Apollo percebe-se que a frequência de pessoas de diferentes

\footnotetext{
${ }^{26}$ A APOTHEOSE PERENNE DO APOLLO. A.J., Barbacena, n. 3, 1923, p. 1.

${ }^{27}$ PHILOCELINA ALMEIDA. A.J., Barbacena, n. 2, 1923, p. 2.

${ }^{28}$ PHILOCELINA ALMEIDA. A.J., Barbacena, n. 2, 1923, p. 2.
} 
cores e possivelmente classes aconteceu mesmo que alguns estratos sociais ainda fossem minorias nesse tipo de casa de diversão.

O número de pessoas presentes nas sessões fílmicas pareceu continuar com êxito, visto que para além da lotação prevista aos domingos, a popularidade da casa ocorria também em dias da semana, e não somente com populares, pois a casa estava "implantando as melhores condições de diversões, ao alcance dos abastados e dos remediados" 29 , e,

[...] Barbacena em peso, representada no que há de mais selecto e de mais fino, na sociedade tem accorrido ás suas sessões. A agglomeração excessiva do povo, torna pequena a sala d' entrada; o que o hontem parecia-nos grande demais, hoje parece-nos pequeno, o próprio salão de projecção na sua imponencia grandiosa, é exiguo, é defficiente para as enchentes habituaes $[\ldots]^{30}$.

Dentre as pessoas da classe abastada que estiveram presentes na primeira sessão fílmica do Apollo, destacaram-se as jovens Aracy Esteves, Maria Luiza Tamm, Vera Tamm, Nair Abranches, Lilica, Sinhasinha Leite, Mme. Laurita Bias, Mme. Tovar, Vera Araripe e Mme. Milanez que estavam em grupinho e apostaram na "seducção mysteriosa do chapéu, singelo e gracioso" "31. Tal afirmação aponta que mesmo que a empresa pedisse para que tal indumentária não fosse premissa na inauguração da casa, que a presença de citadinas que o trajavam também era bem-vinda e ainda ofereceu elogios, pois tal escolha impregnou o ambiente com as exigências do bom gosto ${ }^{32}$.

A equipe de trabalho dessa empresa pareceu inovar os costumes locais, visto que contava com as senhoritas Albanita de Oliveira e Maria Amelia de Oliveira na venda de bilhetes e Manoelita de Araujo Lima e Ida Piacesi no atendimento aos clientes. A respeito de Ida Piacesi, ela era filha de Nello, portanto, sobrinha do proprietário Aroldo, era normalista em formação e no Apollo ocupava a função de garçonette d'honeur ${ }^{33}$. Segundo a empresa as mulheres possuíam características melhores para atender ao público, por isso a escolha foi acertada. Consoante a notícia:

como nem todas as creaturas tem os predicados indispensaveis que o metier delicadissimo de lidar com o publico requer, e dado ainda a exiguidade do nosso meio ainda acanhado, a empreza tem motivos sinceros de se rejubilar e congratular-se ao mesmo tempo com o publico pelo <<tour de force〉> conseguido no feminismo.

${ }^{29}$ O TOUR DE FOURCE DO “APOLLO”. A.J., Barbacena, n. 5, 1923, p. 3.

${ }^{30}$ A APOTHEOSE PERENNE DO APOLLO. A.J., Barbacena, n. 3, 1923, p. 1.

${ }^{31}$ KODAK. A.J., Barbacena, n. 2, 1923, p. 3.

${ }^{32}$ KODAK. A.J., Barbacena, n. 2, 1923, p. 3.

${ }^{33}$ IDA PIACESI. A.J., Barbacena, n. 11, 1923, p. 2. 
Depois, em todas as profissões suaves em que o homem age bem, a mulher o substitue melhor ainda, por ser mais doce, mais paciente, mais meiga, submissa e attrahente ${ }^{34}$.

A partir do anunciado sobre a participação das mulheres no trabalho com cinema são feitas duas considerações. A primeira é a de que não era comum mulheres dessa cidade nessa função, com exceção das atividades da esposa de Paulo Benedetti junto ao marido na filmagem de documentários ${ }^{35}$. Contudo, no trabalho com o entretenimento público, o serviço das mulheres no Apollo se mostra como um dado inédito para as ocupações femininas barbacenenses que foram destacas em estudo anterior que destacou sobretudo os serviços do ensino, operariado, música, imprensa e escrita (SILVA, 2018).

A segunda consideração se relaciona ao sentido conferido a esse tipo de exercício, pois ao citar que tal atividade estava associada ao feminismo é importante apontar que a redatora do jornal apresentava ambiguidades entre compartilhar do feminismo e do sufragismo. De acordo com Pimenta (2007), Ines Piacesi se declarou feminista e não sufragista, o que ao seu ver havia diferenças na postura radical das sufragistas em deixarem de lado as responsabilidades femininas de cuidar do casamento e prole. Entretanto, o autor faz a reflexão de que esse posicionamento se tratava de uma postura ambígua e contraditória para uma mulher que estava a frente da escrita do Apollo Jornal e do O Rubicon, o que para a época contrastava com as tarefas domésticas destinadas ao sexo feminino (PIMENTA, 2007).

A respeito dos filmes reproduzidos no Apollo, esses eram sobretudo dos fornecedores Goldwyn, Fox (filme e jornal) e Serrador, que eram projetados a $2 \$ 000$ em Belo Horizonte, Juiz de Fora e Rio de Janeiro, contrastando com o valor fixo cobrado pelo Apollo ${ }^{36}$. Acrescentase a isso que um documentário local fez parte de sua programação, o título Varios Aspectos de Barbacena (1924), produzido pela empresa conterrânea Scab Film.

Acerca da presença das fitas do Programa Serrador, foi algo muito celebrado pela casa pois era a primeira empresa de cinema em Barbacena a apresentar filmes dessa marca "que

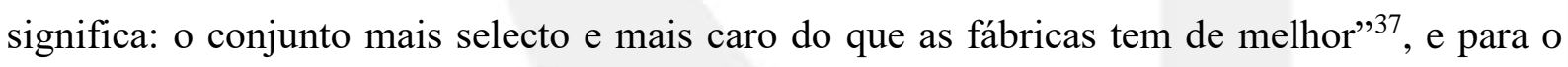
júbilo de sua presença a empresa organizou a Sessão Selecta nas segundas-feiras a partir de 7 de outubro de 1923, destinando esse momento a exibição de filmagens desse selo. Na agenda inaugural do evento consta o título Amor contra o medo ${ }^{38}$.

\footnotetext{
${ }^{34}$ A GUARNIÇÃO VIVA DO APOLLO. A.J., Barbacena, n. 2, 1923, p. 4.

${ }^{35}$ CINEARTE, Rio de Janeiro, 5 jun. 1929, edição 00171 (1), p. 7.

${ }^{36}$ HOJE- HOJE. A.J., Barbacena, n. 6, 1923, p. 1.

${ }^{37}$ O APOLLO AO PUBLICO DISTINCTO E CONSCIENCIOSO. A.J., Barbacena, n. 9, 1923, p. 1.

${ }^{38}$ SESSÃO SELECTA. A.J., Barbacena, n. 9, 1923, p. 1.
} 
Nas notícias sobre o funcionamento da primeira Sessão Selecta identificou-se que a casa foi ornamentada por duas citadinas, Manuelita de Araujo Lima, que trabalhava na casa, e Elisa Magalhães, citadas como "duas amiguinhas ás quaes o Apollo agradece com efusão"39. Também existem pistas que conduzem a análise de que essa programação foi seleta não só pela escolha da marca dos filmes, mas também pela sua descrição, como um programa que se tratava da "imitação do que há em outros centros adeantados" 40 e do mesmo modo pela presença de público apurado a dedo, ou conforme o Apollo Jornal: "tudo o que Barbacena tem de mais fing $[\ldots]^{\prime, 41}$.

O preço das entradas dessa sessão foi superior em relação ao taxado nas programações comuns, sendo cobrado o valor de $1 \$ 500$ ao invés de $1 \$ 100$. O motivo era que o custo das fitas da Serrador era maior e segundo a empresa tal cobrança também seria para a aquisição de brindes para serem sorteados na programação. Contudo, no decorrer dos detalhes sobre a Sessão Selecta identificou-se que ao bello sexo era cobrado 800 réis $^{42}$ e que os brindes eram doados por comerciantes locais e citadinos não ligados ao comércio. Do primeiro grupo citam-se as lojas A Confiança, Ao $1^{\circ}$ Barateiro, Salão Americano, Confeitaria Apollo, Casa Mendes, Pharmacia Baeta Alvim, Armazem S. José, Fabrica de Meias Santa Iria, Leiteria Santa Clara ${ }^{43}$, e a própria empresa Apollo que incluiu como brindes a caderneta de bilhetes ${ }^{44}$. Ainda assim, essa programação pareceu não desagradar ao público interessado em cinema, que em síntese demonstrou preferência pelos filmes da Serrador ${ }^{45}$.

Outro aspecto que atesta a seleção do público é que nessa sessão foi destacada sobretudo a presença dos citadinos e das citadinas da classe mais abastada que participaram dos sorteios de brindes de modo igual ${ }^{46}$. Em especial as bem vestidas senhoras, senhoritas, mademoiselles e madames, essas se deixaram ser fotografadas na inauguração da Sessão Selecta e quantitativamente se sobrelevaram ao número de cavalheiros presentes nas segundas-feiras.

Para além do fato de que as mulheres pareceram ser público assíduo e maioria nas Sessão Selecta, o Cine Apollo anunciou que estava sendo pensada a organização de Sessões especiaes e variadas, onde as citadinas, nomeadas como gentil sexo, poderiam assistir filmes e

\footnotetext{
${ }^{39}$ SESSÃO SELECTA. A.J., Barbacena, n. 10, 1923, p. 2.

${ }^{40}$ C.C. A.J., Barbacena, n. 12, 1923, p. 1.

${ }^{41}$ SESSÃO SELECTA. A.J., Barbacena, n. 10, 1923, p. 2.

${ }^{42}$ CINEMAS. C. B., Barbacena, n. 1988, 1824, p.2

${ }^{43}$ BRINDES. A.J., Barbacena, n. 12, 1923, p. 4.

${ }^{44}$ C.C. A.J., Barbacena, n. 12, 1923, p. 1.

${ }^{45}$ C.C. A.J., Barbacena, n. 12, 1923, p. 1.

${ }^{46}$ A.J., Barbacena, n. 11, 1923, p. 1-2.
} 
se expressar artística e literariamente ${ }^{47}$. Também foi destacado que a presença das conterrâneas na porta da casa, na sala de espera e nas programações corriqueiras alegrava o recinto.

As normalistas inseridas na profisssão e as em formação foram evidenciadas como frequentadoras muito presentes no Apollo, assim como contribuíram com os seus serviços. Por exemplo, a professora Philocelina Mattos escreveu textos para o Apollo Jornal e prestou homenagem a casa no seu aniversário de um ano de fundação com a escrita de um soneto ${ }^{48}$, Ida Piacesi se dedicou ao atendimento ao público e Elisa Magalhães, além de ajudar na decoração do Apollo, foi a responsável por conduzir a Orquestra Independente que deu o tom musical das Sessões Selectas ${ }^{49}$ e a outros eventos sediados na empresa, como um festival litero-musical beneficente organizado por mulheres ${ }^{50}$.

Interpreta-se que a presença das citadinas no Apollo foi influenciada ou mesmo evidenciada por esta casa pelo fato de Ines Piacesi e Ida Piacesi serem parte do grupo de professoras da cidade. Semelhante a outros cineteatros da região que sediaram programações organizadas por mulheres, especialmente professoras, e ofertaram programas específicos para as citadinas intitulados de Sessões Chiques, onde às mesmas tinham entrada gratuita e comparecimento destacado (SILVA; SOUTTO MAYOR, no prelo), no Apollo, mesmo que também tenham sido organizadas sessões dedicadas a este público, a frequência das mulheres foi algo evidenciado e estimulado de modo habitual. Exemplificativamente, na primeira quinzena de funcionamento da casa, em específico o dia 28 de agosto de 1923, a empresa anunciou que "reconhecida pelas provas de sympathia que tem recebido de nossa população, dará hoje, entrada franca ás senhoras e senhorinhas, mimoseando-as com um primoroso film Goldwyn, em 6 partes - A DESPREZADA" ${ }^{51}$. Ainda sobre a organização de sessões para as mulheres, o Apollo conferiu programações "em homenagem ao bello sexo", como a Sessão de Arte de 31 de janeiro de 1924, com "Programma Extra Especial - A MULHER NU'A, por Francisca Bertine - a grande tragica italiana. O film é um obra de valor, tirado do celebre romance de H. Bataille" $" 52$.

Em outro sentido, a frequência do público infantil na agenda do Apollo foi incluída das seguintes formas: programas planejados para as escolas "no intuito de prestar serviço á

\footnotetext{
${ }^{47}$ A.J., Barbacena, n. 2, 1923, p. 4.

${ }^{48}$ PELOS CINEMAS. C.B., Barbacena, n. 2019, 1924, p. 1.

${ }^{49}$ SESSÃO SELECTA. A.J., Barbacena, n. 14, 1923, p. 1-2.

${ }^{50}$ LIGA B. C. ANALPHABETISMO. A. J., Barbacena, n. 14, 1923, p. 3.

${ }^{51}$ CINE-THEATRO-APOLLO. C.B., Barbacena, n. 1921, 1923, p. 2.

${ }^{52}$ DIVERSÕES. C.B., Barbacena, n. 1965, 1924, p. 2.
} 
instrucção" ${ }^{53}$, as matinées nos domingos e feriados, matinée a phantasia nos dias de carnaval ${ }^{54}$, e por fim, a matinée blanche, programada para às quintas-feiras no horário de 13:30 horas em que além de filmes abrigou sorteios para as crianças. Na notícia que fez convite para a matinée blanche notou-se que esse momento era convite a participação dos queridos homensinhos ${ }^{55}$, dado os benefícios do cinema nessa fase da vida pelo seu caráter educativo, e ainda foi prescrito que as futuras mães deveriam ter a consciência de enviar os filhos as sessões de cinema a fim de instruí-los e não permitir que ficassem se distraindo na entrada da casa de cinema. Conforme a fonte:

sobre ser uma diversão culta, uma escola de moral, o cinema è para a creançada, mais do que tudo uma revelação intima, a eclosão do seu proprio $e u$ desconhecido. Por isto, leitoras que tendes o dia de ser mães, mandai ao cinema os vossos filhinhos; Isto será sempre incomparavelmente melhor[,] mais proveitosa do que qualquer outra distracção que elles arranjem pela entrada. Depois ao regressarem prosas, vibrantes, enthusiasmadas, relatandonos com garbo as aventuras da fita, não vos sentis, não nos sentimos todas, orgulhosas, internecidas, com elles os nossos homensinhos $?^{56}$

O auxílio as propostas que queriam educar a população também fizeram parte das intenções do Apollo, visto que, por exemplo, uma porcentagem da renda da Sessão Selecta de 28 de outubro foi destinada a Liga Barbacenense Contra o Analphabetismo ${ }^{57}$ que estava retomando as suas atividades com uma nova diretoria ${ }^{58}$, assim como foi organizado um festival litero-musical em benefício dessa causa ${ }^{59}$.

No contínuo do funcionamento do Cine Apollo existiram outras programações que envolvem as crianças e que estiveram associadas ao trabalho docente de Ines Piacesi. De acordo com Pimenta (2007), entre as décadas de 1930 e 1940 essa professora promoveu sessões de cinema com a renda revertida para o caixa escolar da instituição que lecionava, o Grupo Bias Fortes, e organizou os Auditórios Escolares, momentos considerados como prolongamento das aulas para às suas turmas, que incluíam "apresentação de poemas, de algumas esquetes teatrais de autoria de Ines Piacesi acerca de noções de corpo humano, os reinos da natureza etc., além da apresentação do Hino a Barbacena”, escrito pela mesma (PIMENTA, 2007, p. 84).

\footnotetext{
${ }^{53}$ A.J., Barbacena, n. 5, 1923, p. 2.

${ }^{54}$ APOLLO. C. B., Barbacena, n. 2072, 1925, p. 2.

${ }^{55}$ O CINEMA NA INFANCIA. A.J., Barbacena, n. 10, 1923, p. 1-2.

${ }^{56}$ O CINEMA NA INFANCIA. A.J., Barbacena, n. 10, 1923, p. 1-2.

${ }^{57}$ Como ação da Liga Brasileira Contra o Analfabetismo, fundada no Rio de Janeiro em 7 de setembro de 1915 com o objetivo de oferecer ensino gratuito às pessoas analfabetas, a Liga Barbacenense Contra o Analfabetismo foi inaugurada no dia 12 de outubro de 1915 e sua sede em 1920 (SILVA, 2018).

${ }^{58}$ L. B. C. ANALPHABETISMO. A.J., Barbacena, n. 12, 1923, p. 2.

${ }^{59}$ LIGA B. C. ANALPHABETISMO. A. J., Barbacena, n. 14, 1923, p. 3.
} 
Dentre às outras atividades sediadas no Apollo constam as exposições de quadros do artista Alberto Delpino Junior que apresentou pinturas feitas a óleo e aquarela e também caricaturas no salão do cineteatro ${ }^{60}$, apresentações de danças, grupos de teatro, número de ilusionistas, como o do equatoriano Raca C. Aguirre, "que vem procedido de reclamo pelos logares onde se tem exhibido. [...] tendo já percorrido todo o Novo Mundo, exhibindo-se nas principaes cidades das tres Americas"61.

O Cine-Theatro Apollo também participou de alguns acordos com outras empresas da região. Como exemplo, identificou-se a "fina tatica commercial" 62 do Sr. Sebastião Antunes Siqueira, proprietário da loja de variedades $A$ ' Confiança, em oferecer aos seus clientes como brinde ingressos das sessões do Apollo e da Loteria do Estado de Minas. Tal estratégia fazia incentivo à frequência das pessoas ao cinema, caracterizando, segundo a Apollo Jornal, "um louvavel sentimento de philantropia e progresso" 63 e obteve êxito, pois as vendas do recinto cresceram e os fregueses compravam na intenção de também terem os brindes do anúncio ${ }^{64}$, o que certamente reverberou no número de frequentes do Apollo.

O Cine-Theatro Apollo foi arrendado em 16 de julho de 1925 pela empresa A. Leal \& C. Sob nova direção essa casa de diversões foi reinaugurada em 19 de julho de 1925 com o nome de Cine-Theatro Leal (SILVA, 2018). Em meados da década de 1930, Aroldo Piacesi retomou as atividades do Cine Apollo em seu prédio original, inaugurando um aparelho exibidor de cinema falado em 4 de fevereiro de 1931, o movictone $e^{65}$. Já a partir do ano de 1967 o Apollo passou a ser propriedade da família de Urias de Castro.

Em entrevista a Maria da Glória Bittar de Castro (nascida em 1966), doravante Gogóia, soube-se que na década de 1950 a Confeitaria Apollo, naquele momento nomeada de Bomboniére Americana, era propriedade de José da Silva Campos, o qual por motivo de força maior vendeu o negócio para Urias de Castro (CASTRO, 2020).

Urias Barbosa de Castro (1925-2006), natural de Mercês, Minas Gerais, mudou-se com a esposa Suria Bittar de Castro e filhos para Barbacena a fim de empreender após encontrar o anúncio da venda da Bomboniére Apollo na década de 1950. O comércio que ficava instalado no perímetro do Cine Apollo se tratava de um recinto frequentado sobretudo por homens barbacenenses que também usavam a entrada do âmbito para paqueras (CASTRO, 2020).

\footnotetext{
${ }^{60}$ AS EXPOSIÇÕES DE QUADROS DE ALBERTO DELPINO JUNIOR. A.J., Barbacena, n. 11, 1923, p. 3.

${ }^{61}$ DIVERSÕES. C.B., Barbacena, n. 1959, 1924, p. 2.

${ }^{62}$ INEDITISMO. A.J., Barbacena, n. 4, 1923, p. 3.

${ }^{63}$ INEDITISMO. A.J., Barbacena, n. 4, 1923, p. 3.

${ }^{64}$ A “A' CONFIANÇA COM CONFIANÇA. A.J., Barbacena, n. 8, 1923, p. 1.

${ }^{65}$ PELOS CINEMAS. C.B., Barbacena, 1931, n. 2653, p.2.
} 
Por perceber que o cinema era um negócio rentável, o negociante Urias de Castro comprou também a casa de diversões e a reinaugurou em $1^{\circ}$ de fevereiro de 1969 mantendo o mesmo nome, visto que a marca Apollo era referência na cidade e com grande frequentação. Na ocasião a fita projetada foi Ao mestre com carinho (1967) (CASTRO, 2020).

Na década de 1980 às atividades do Cine Apollo foram interrompidas e a casa foi reinaugurada em 28 de outubro de 1988 pela iniciativa da filha caçula da família Castro, Gogóia, responsável por restaurar a arquitetura do prédio e fazer da casa de diversões o que chamou de cinema de arte, em que além de filmes foram sediadas diferentes experiências artísticas ao público, como teatro e música. A projeção da inauguração dessa gestão foi Cocoon (1985) (CASTRO, 2020).

De acordo com Gogóia, o seu pai foi quem concedeu a permissão para que a mesma retornasse às atividades do Cine Apollo, visto que o prédio era sua propriedade. Na época, com 20 anos de idade, a mesma afirma que vivenciou muitos desafios por ser uma mulher jovem à frente de uma casa de cinema. Essa ainda cita a dificuldade em comprar filmes, em que, por exemplo, as empresas distribuidoras localizadas em Belo Horizonte, capital de Minas Gerais, deixavam a desejar com as suas compras, acreditando que o principal motivo desse descrédito era por ser jovem e mulher (CASTRO, 2020).

Devido ao surgimento e sucesso de novas tecnologias como as fitas VHS, a vida do Cine Apollo ficou cara perante a nova realidade, por isso, a família Castro decidiu que era hora de fechar em definitivo as portas do Apollo, permitindo a instalação de outros negócios em seu prédio (CASTRO, 2020).

\section{[Temporariamente] "Corta!"}

O Cine-Theatro Apollo foi a casa projetora de filmes de Barbacena que esteve aberta em maior número de anos. A sua permanência significa a existência de público interessado como também de pessoas que acreditaram no cinema como um negócio. Destaca-se que essa empresa trouxe novidades para a vida citadina barbacenense no início do século XX no que tange ao divertimento cinema, como a oferta de cadernetas de bilhetes, aquisição de fitas da marca Serrador e a presença de mulheres trabalhando publicamente com cinema. Novas pesquisas precisam ser feitas sobre as atividades do Apollo, especialmente as que contemplem as décadas de 1930 em diante. 


\section{Referências bibliográficas}

BARRO, M. Participação italiana no cinema brasileiro. Editora SESI - Serviço Social da Indústria, 2017, 328 p.

BOUILLET, R. F. 'Ida ao cinema' da população negra brasileira na primeira metade do século XX. Revista da ABPN, Uberlândia, v. 12, n. 33, jun-ago 2020, p. 383-401.

CASTRO, M. G. B. de. Entrevista concedida a Igor Maciel da Silva em 12 de outubro de 2020. GALDINO, M. da R. Paulo Benedetti - dossiê. In: ROCIO, C.; KANO, C. S.;ANDRADE, R.; GALVÃO, M. R; e outros. Cinema brasileiro: 8 estudos, Rio de Janeiro, MEC EMBRAFILME - FUNARTE, 1980, p. 109-144.

GOMES, P. A. Os italianos e o nascente cinema mineiro. Revista da imigração italiana em Minas Gerais - Ponte entre culturas, Belo Horizonte, 2011, p. 1-8.

GOMES, P. A. Paulo Benedetti. In: GOMES, P. A. Pioneiros do cinema em Minas Gerais, Belo Horizonte: Crisálida, 2008, p. 41-49.

ORLANDO, J. A. A cidade dos Lunáticos. In: NAZARIO, Luiz (org.). A cidade imaginária, São Paulo: Perspectiva, 2005, p. 13-26.

PIMENTA, E. F. Duas faces de uma mesma moeda: recepção e circulação do ideário fascista e integralista em Barbacena-MG através do casal Ines e Aroldo Piacesi, 1924-1945. 2015. 262 f. Dissertação (mestrado), Universidade Federal de São João Del Rei, São João Del Rei-MG, 2015.

PIMENTA, E. F. Ines Piacesi, 1895, 1981: um ensaio biográfico. 2007. 110 f. Monografia (bacharelado em História), Universidade Federal de Ouro Preto, Mariana -MG, 2007.

RESENDE, E. M. Do debate político à notícia: a imprensa periódica em Barbacena - séculos XIX e XX. Revista Mal-Estar e Sociedade, ano V, n.8, janeiro/ junho 2012, p.15-40.

RIBEIRO, J. S. História Econômica do Município de Barbacena v.1 (1889-1930) - Tempos de Esperança/Silvério Ribeiro)/Barbacena: Gráfica e Editora Cidade de Barbacena, 2012, 704p. SAVASSI, A. J. Barbacena 200 anos. Belo Horizonte: Editora Lemi S.A., 1991, v.1, 287 p.

SEVCENKO, N. Orfeu extático na metrópole: São Paulo, sociedade e cultura nos frementes anos 20. São Paulo: Companhia das Letras, 1992.

SILVA, I. M. Elas se divertem (Barbacena - MG, 1914 a 1931). 2018. 136 f. Dissertação (mestrado), Programa de Pós-graduação em Estudos Interdisciplinar do Lazer, Escola de Educação Física, Fisioterapia e Terapia Ocupacional, Universidade Federal de Minas Gerais, Belo Horizonte-MG, 2018.

SILVA, I. M.; SOUTTO MAYOR, S. T. As mulheresde Barbacena (MG) e as "Sessões Chiques" de cinema (anos de 1926 e 1927). Motrivivência, Florianópolis-SC, no prelo. 